\title{
ELECTRONEUROMYOGRAPHY EXAMINATION OF DIABETIC POLYNEUROPATHY PATIENTS
}

\author{
Siti Nurlaela ${ }^{1}$, Shahdevi Nandar Kurniawan ${ }^{1}$, Machlusil Husna ${ }^{1}$ \\ Correspondence: sitinurlaela.dr@gmail.com \\ ${ }^{I}$ Department of Neurology Faculty of Medicine Brawijaya University, Malang, Indonesia.
}

\section{Article History:}

Received: September 22, 2017

Accepted: May 25, 2018

Published: January 1, 2019

\section{Cite this as:}

Nurlaela S, Kurniawan SN, Husna M.

Electroneuromyography examination of diabetic polyneuropathy patients. Malang Neurology Journal; 2019.5:1-4. DOI:

http://dx.doi.org/10.21776/ub.mnj .2019.005.01.1

\section{ABSTRACT}

Background: Diabetic polyneuropathy (DPN) is one of the chronic complications that occur in approximately $80 \%$ of diabetes mellitus (DM) patients. This condition is a results of metabolic, vascular, and immunological disorders.

Objective: To determine the profile of electroneuromyography (ENMG) examination of DPN patients at neurology clinic of Saiful Anwar General Hospital.

Methods: This cross-sectional observational descriptive study was carried out at Saiful Anwar General Hospital Malang from June 1, 2015 to December 31, 2015, with purposive sampling method. A total of 43 DM patients with symptoms of polyneuropathy fulfilling inclusion criteria and no exclusion criteria were examined for ENMG. ENMG examirnation were including distal latency, amplitude and nerve conduction velocity of 4 motoric nerves (median, ulnar, tibial, peroneal) \& 3 sensory nerves (median, ulnar, sural), and $\mathrm{F}$ waves of ulnar, median and peroneal nerves of the left and right extremities.

Results: Of the 43 patients evaluated in this study, the mean sensory sural nerve conduction velocity was $13.01 \mathrm{~m} / \mathrm{s}$. The majority type of nerve damage in diabetic polyneuropathy patients in this study were mixed type $52.33 \%$ in the median nerve, $60.47 \%$ in the ulnar nerve, $72.10 \%$ in the tibial nerve, and $54.65 \%$ in the peroneal nerve in motor nerve studies and $80.23 \%$ in the median nerve and $88.37 \%$ in the peroneal nerve in the sensory nerve studies).

Conclusion: The nerve damage that occurs in DPN patients at Saiful Anwar general Hospital is severe, with the majority being the axonal demyelinating type, especially in the sensory nerve fibers in the inferior extremities.

Keywords: Diabetic polyneuropathy, electroneuromyography, axonal, demyelinating

\section{Introduction}

The prevalence of diabetes mellitus (DM) in the world continues to increase, one of which occurred also in Indonesia. ${ }^{1,2,3}$ By 2015, an estimated 415 million people are suffering from DM and this is estimated to increase to 642 million by 2040. In fact, by 2015 Indonesia is the seventh largest DM patient in the world which reached 10million inhabitants.

Diabetic neuropathy is a disorder of the peripheral, autonomic and cranial nerves associated with DM. ${ }^{1,4} \mathrm{DM}$ neuropathic complications can be classified into chronic and acute neuropathy. The most common chronic neuropathy is distal symmetric polyneuropathy or commonly referred to as diabetic polyneuropathy (DPN). 5,6,7

Approximately $80 \%$ of patients with DM have clinical and subclinical peripheral polyneuropathies. ${ }^{7}$ The incidence of neuropathy known to have association with the duration of DM, poor blood sugar control, and other comorbid complications such as retinopathy and nephropathy. ${ }^{7,8,9}$ The study by Pirart showed that $7.5 \%$ of patients had neuropathy at the start of DM diagnosis, and after 25 years of having DM, the prevalence increased to $50 \%$. $^{10}$
Until now, there is no data on the total prevalence of DPN in Indonesia, as well as the profile DPN patients in Indonesia, especially from the description of the electroneuromyography examination. In this descriptive research will be discussed about the profile of DPN patients in Saiful Anwar General Hopsital Malang, viewed from the description of electroneurographic examination.

\section{Methods}

A cross-sectional observational descriptive study was conducted in outpatient clinic of Neurology Department of Saiful Anwar General Hospital with purposive sampling method. This research was conducted since June 1, 2015 until December 31, 2015. DM patients who met the possible DPN criteria according to the Toronto (2002) classification of patients with symptoms and/or signs of DPN in various clinical degrees in neurologic clinics who are willing to follow this study were examined. Symptoms include decreased sensation, positive sensory symptoms of neuropathy (e.g numbness, puncture, burning, or pain) especially in the tip of the toes, soles of the feet, or legs. Signs include a decrease in symmetrical bilateral sensation, loss/decrease in the achilles reflex, as well as weakness/weakening of the lower limb muscles. The 
exclusion criteria in this study were anatomic abnormalities of the lower limbs, pregnancy, history of stroke with residual neurologic deficit, malnutrition patients with suspicion of vitamin B12 deficiency, history of malignancy and or chemotherapy, and use of neurotoxic drugs in the last 3 months. 6,7

The electroneuromyographic study was performed by a neurophysiologist using Nihon Kohden/Neuropack M1 MEB-9200 version 08.06 (copyright 1997-2007) in the electrophysiology laboratory of Saiful Anwar General Hospital to evaluate the speed of nerve conductivity. Patient data were kept confidential and modified in the form of unique code known only to the research team to reduce the bias in this study. The results of this electroneuromyographic study were then recorded and analyzed.

\section{Results}

There were 74 patients with DM and complaints of diabetic polyneuropathy who went to Saiful Anwar General Hospital since June 1, 2015 until December 31, 2015. 27 had a history of stroke ( 8 haemorrhagic stroke and 19 infarction stroke) and 4 had nerve clamping marks ( 3 carpal tunnel syndrome and 1 cervical root syndrome). So there were 43 patients with DM and diabetic polyneuropathy who met the inclusion criteria were included in the study.

Overall population in this study had type 2 DM with a male/female ratio was 1.15 . The average age of the patients in this study was 60.84 years with an age range between 41 78 years. The mean duration of diabetes was 8.28 years, body mass index (BMI) was $25.34 \mathrm{~kg} / \mathrm{m} 2$, percentage of $\mathrm{HbA} 1 \mathrm{C}$ was $8.95 \%$, and fasting blood glucose level was $184.14 \%$ as shown in table 1 . Twelve patients $(28 \%)$ had smoking habit and 29 patients $(67.4 \%)$ suffered from hypertension.

Table 1. Patients characteristic.

\begin{tabular}{lc}
\hline \multicolumn{1}{c}{ Variable } & Mean \pm SD \\
\hline Age (years) & $60,84 \pm 8,43$ \\
Sex $\quad$ Male & $53,5 \%$ \\
$\quad$ Female & $46,5 \%$ \\
Duration of DM (years) & $8,28 \pm 9,57$ \\
Duration of symptoms (years) & $2,96 \pm 5.37$ \\
Therapy of DM & \\
$\quad$ Diet & $4,7 \%$ \\
OAD & $46,5 \%$ \\
Insulin & $48,8 \%$ \\
BMI (kg/m ${ }^{2}$ & $25,34 \pm 4,40$ \\
Hipertension & \\
Yes & $67,4 \%$ \\
No & $32,6 \%$ \\
FBG (mg/dl) & $184,14 \pm 65,04$ \\
2PP BG (mg/dl) & $255,14 \pm 96,54$ \\
HbA1C (\%) & $8,95 \pm 1,68$ \\
Sural nerve velocity (m/s) & $15,78 \pm 20,59$ \\
\hline
\end{tabular}

OAD: Oral Anti Diabetes; BMI: Body Mass Index; DM Diabetes Mellitus; FBG: Fasting Blood Glucose; 2PP BG: 2 hours post pandrial blood glucose.

The results of the electroneuromyographic examination are shown in Table 2. Average value of electroneuromyographic examination in DPN patients were lower than normal in all aspects, with the most significant decrease in sural conduction velocity, $13.01 \mathrm{~m} / \mathrm{s}$. Normal motor nerve study was found in $18.6 \%$ of the median nerve,
$18.6 \%$ of the ulnar nerve, $2.33 \%$ of the tibial nerve and 2 , $33 \%$ of the peroneus nerve. While normal sensory study was obtained at $2.33 \%$ of the median nerve and $0 \%$ in the sural nerve. From this result, it can be concluded that (1) abnormalities in the sensory nerves are more common than motor nerve and (2) more abnormalities are found in the inferior extremity.

The majority type of nerve damage in DPN patients in this study were mixed type $(52.33 \%$ in the median nerve, $60.47 \%$ in the ulnar nerve, $72.10 \%$ in the tibial nerve, and $54.65 \%$ in the peroneal nerve in motor nerve conduction study and $80.23 \%$ in the median nerve and $88.37 \%$ in the peroneal nerve in sensory nerve conduction study).

\section{Discussion}

In this study, it was found that abnormalities in the inferior extremity were higher than the superior extremity. This is consistent with the results of Baba and Ozaki studies (2001), which found that nerve conduction abnormalities in DPN would begin in the inferior extremity. This phenomenon is caused by long dependent dying back process in the pathophysiology of DPN..$^{11,12,13}$ This type of axonopathy leads to an increased predisposition of DPN in taller patient. ${ }^{14,15}$

Diabetic polyneuropathy may affect sensory, motor, or autonomic nerve fibers. In this study, it was found that abnormalities in sensory nerve fibers were more numerous than in motor nerve fibers, as the results indicated by other studies. ${ }^{11,16,17,21,22}$

The majority type of nerve damage in this study was mixed type $(52.33 \%$ in the median nerve, $60.47 \%$ in the ulnar nerve, $72.10 \%$ in the tibial nerve, and $54.65 \%$ in the peroneal nerve in the motor nerve conduction study and $80.23 \%$ in the median nerve and $88.37 \%$ in the peroneal nerve in the study of sensory nerve). This was in contrast to several other studies, which shows that the nerve susceptibility of diabetes mellitus generally results as axonopathy. 5,16

Distal sensorimotor diabetic polyneuropathy is a typical form of axonal polyneuropathy affecting large or small sensory nerve fibers. However, there may also be secondary demyelinating. ${ }^{18,19}$ The decrease in motor conduction velocity shows a decrease in nerve conduction in large myelinated nerve fibers, so that the reduction in conduction is usually mild and rarely meets the criteria for chronic demyelinating. However, it has been showed that in patients with type 1 diabetes with uncontrolled hyperglicemia, it indicates a decrease in nerve conduction that suggests an effect on myelin on uncontrolled hyperglycemia. The study by Wilson et al also showed an association between the speed of nerve conduction and the distal compound muscle action potential (CMAP) with the conclusion that diabetic neuropathy exhibits a decrease in nerve conduction velocity that can not be explained only through the axon loss mechanism. In diabetic nerve damage, peripheral antigen exposure occurs by the immune system, so diabetic neuropathy may be a predisposing factor to neuropathy mediated by the immune system. Based on this, it can be concluded that there are different pathophysiology involved in the occurrence of diabetic neuropathy. ${ }^{8,18,19,20}$ 
The presence of axonal demyelinating polyneuropathies indicates that the nerve damage in this study was severe and prolonged. It could be concluded that the majority of patients in this study had severe diabetic polyneuropathy.

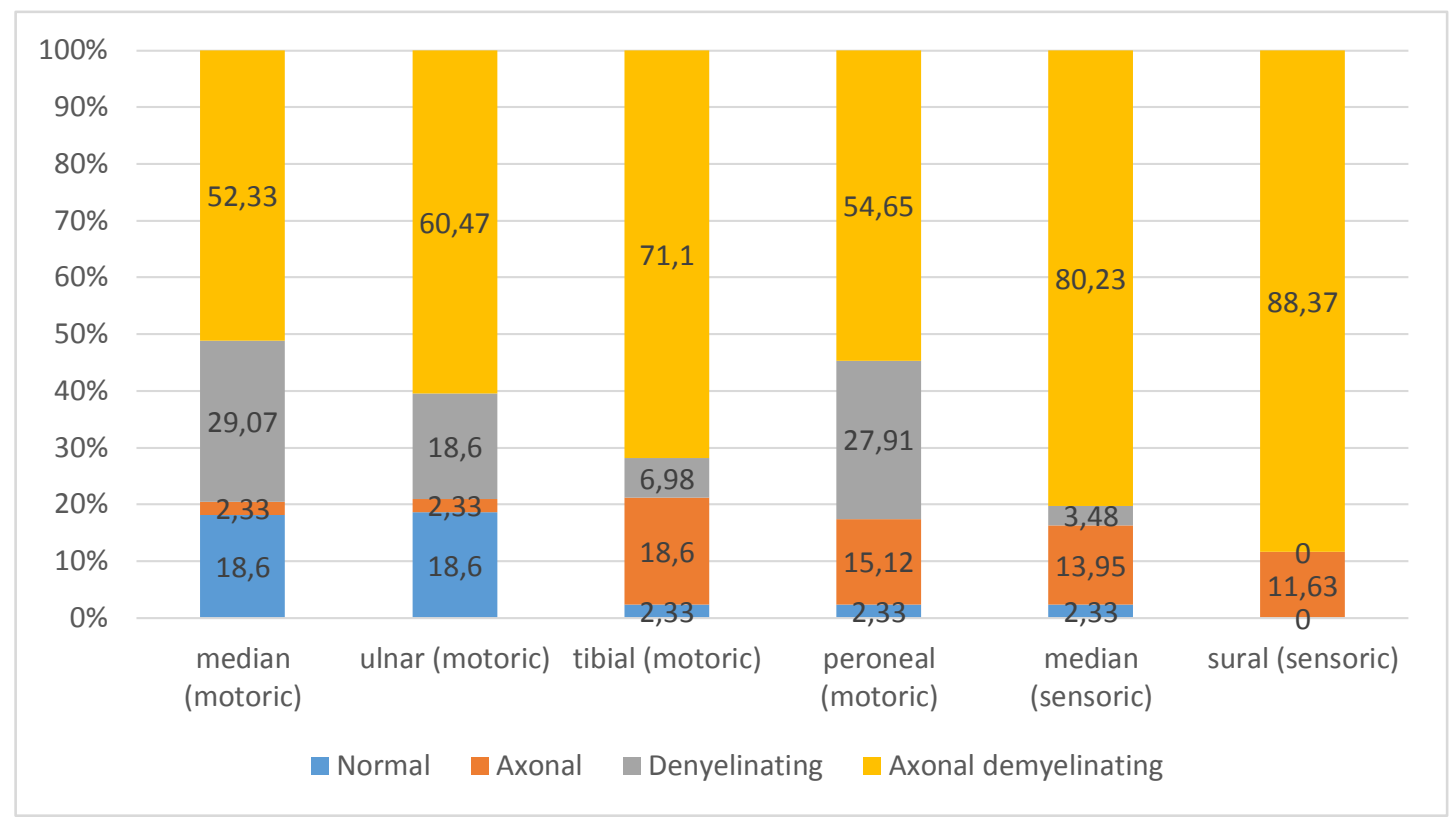

Figure 1. Nerve damage distribution at diabetic polyneuropathy.

Table 2. Results of electroneuromyography studies.

\begin{tabular}{|c|c|c|c|c|c|c|c|}
\hline & \multicolumn{3}{|c|}{ Sensory (SNAP) } & \multicolumn{3}{|c|}{ Motor (CMAP) } & F wave \\
\hline & DL & Amp & velocity & DL & Amp & velocity & \\
\hline Median & $\begin{array}{c}3,03 \pm 1,03 \\
(\mathrm{~N} \leq 3,5)\end{array}$ & $\begin{array}{c}8,94 \pm 3,43 \\
(\mathrm{~N} \geq 20)\end{array}$ & $\begin{array}{c}27,33 \pm 11,82 \\
(\mathrm{~N} \geq 50)\end{array}$ & $\begin{array}{c}4,01 \pm 1,17 \\
(\mathrm{~N} \leq 4,4)\end{array}$ & $\begin{array}{c}5,57 \pm 3,72 \\
(\mathrm{~N} \geq 4,0)\end{array}$ & $\begin{array}{c}41,17 \pm 13,92 \\
(\mathrm{~N} \geq 49)\end{array}$ & $\begin{array}{c}27,08 \pm 6,92 \\
(\mathrm{~N} \geq 25)\end{array}$ \\
\hline Ulnar & $\begin{array}{c}3,09 \pm 1,24 \\
(\mathrm{~N} \leq 3,1)\end{array}$ & $\begin{array}{c}10,08 \pm 5,72 \\
(\mathrm{~N} \geq 17)\end{array}$ & $\begin{array}{c}27,63 \pm 13,24 \\
(\mathrm{~N} \geq 50)\end{array}$ & $\begin{array}{c}3,23 \pm 1,02 \\
(\mathrm{~N} \leq 3,3)\end{array}$ & $\begin{array}{c}6,46 \pm 3,34 \\
(\mathrm{~N} \geq 6,0)\end{array}$ & $\begin{array}{c}42,44 \pm 12,09 \\
(\mathrm{~N} \geq 49)\end{array}$ & $\begin{array}{c}26,45 \pm 5,27 \\
(\mathrm{~N} \geq 25)\end{array}$ \\
\hline Peroneal & - & - & - & $\begin{array}{c}3,98 \pm 2,03 \\
(\mathrm{~N} \leq 6,5)\end{array}$ & $\begin{array}{c}2,14 \pm 1,16 \\
(\mathrm{~N} \geq 2,0)\end{array}$ & $\begin{array}{c}35,41 \pm 9,77 \\
(\mathrm{~N} \geq 44)\end{array}$ & $\begin{array}{c}44,24 \pm 11,35 \\
\quad(\mathrm{~N} \geq 50)\end{array}$ \\
\hline Tibial & - & - & - & $\begin{array}{c}4,37 \pm 2,71 \\
(\mathrm{~N} \leq 5,8)\end{array}$ & $\begin{array}{c}6,08 \pm 2,08 \\
(\mathrm{~N} \geq 4,0)\end{array}$ & $\begin{array}{c}29,03 \pm 11,04 \\
(\mathrm{~N} \geq 41)\end{array}$ & - \\
\hline Sural & $\begin{array}{c}2,43 \pm 2,21 \\
(\mathrm{~N} \leq 4,4)\end{array}$ & $\begin{array}{c}9,79 \pm 7,12 \\
(\mathrm{~N} \geq 6)\end{array}$ & $\begin{array}{c}13,01 \pm 10,83 \\
(\mathrm{~N} \geq 40)\end{array}$ & - & - & - & - \\
\hline
\end{tabular}

DL: distal latency; Amp: amplitude; N: normal value (according to Preston and Shapiro, 2013)

\section{Conclusion}

The results of electroneuromyography examination in diabetic polyneuropathy patients showed abnormalities in the inferior extremity more than the superior extremity, abnormalities in the sensory nerve fibers more than in the motor nerve fibers with the majority was axonal demyelinating type.

This study has limited research that is relatively small number of samples that is only 43 patients. Therefore, further research is needed with sufficient number of samples to get a clearer picture of the picture of elektroneuromiography in diabetic polyneuropathy patients.

\section{Acknowledgement}

The author thanks to the Brawijaya University and Saiful Anwar General Hospital, Malang, East Java, Indonesia for facilitating this research.

\section{References}

1. Veves A, Malik RA. Diabetic neuropathy clinical management. new jersey: Humana Press; 2007

2. American Diabetes Association. 2. Classification and diagnosis of diabetes. Diabetes Care; 2015.38(January):S8-S16. DOI: 10.2337/dc15-S005

3. International Diabetes Federation. IDF Diabetes Atlas. Int Diabetes Fed. 2015:144

4. Said G, Goulon-Goeau C, Slama G, Tchobroutsky G. Severe early-onset polyneuropathy in insulindependent diabetes mellitus: a clinical and pathological study. The New England Journal of Medicine; 1992.326:1257-1263. DOI: 10.1056/NEJM199205073261905

5. Pasnoor M, Dimachkie MM, Kluding P, Barohn RJ. Diabetic neuropathy part 1 overview and symmetric phenotypes. Neurol Clin; 2013.31:425-445. DOI: 10.1016/j.ncl.2013.02.004

6. Bromberg MB, Smith AG. Handbook of peripheral neuropathy. Boca Raton: Taylor and Francis Group; 2005

7. Vinik A, Ullal J, Parson HK, Casellini CM. Diabetic neuropathies: clinical manifestations and current treatment options. Nat Clin Pract Endocrinol Metab; 2006.2(5):269-281 
8. Huang C, Chen T, Weng M, Lee C. Effect of glycemic control on electrophysiologic changes of diabetic neuropathy in type 2 diabetic patients. Kaohsiung $\mathbf{J}$ Med Sci; 2005.21(1):15-21. DOI: http://dx.doi.org/10.1016/S1607-551X(09)70271-2

9. The Diabetes Control and Complications Trial Research Group. The effect of intensive treatment of diabetes on the development and progression of longterm complications in insulin-dependent diabetes mellitus. The New England Journal of Medicine; 1993.328(23):1676-1685.

DOI: 10.1056/NEJM199309303291401

10. Pirart J. Diabetes mellitus and its degenerative complications: a prospective study of 4,400 patients observed between 1947 and 1973. Diabetes Care; 1978.1(4):168-188

11. Baba M, Ozaki I. Electrophysiological changes in diabetic neuropathy: from subclinical alterations to disabling abnormalities. Arch Physiol Biochem; 2001.109(3):234-240.

DOI: 10.1076/apab.109.3.234.11595

12. Bansal V, Kalita J, Misra UK. Diabetic neuropathy. Posgr Med J; 2006.82:95-100. DOI: 10.1136/pgmj.2005.036137

13. Hong CY, Chia SE, Fong SK. Neuropathy in noninsulin-dependent diabetes mellitus. The significance of symptoms. Scand J Prim Health Care; 2009.16(4):233-237.

http://www.ncbi.nlm.nih.gov/pubmed/9932317

14. Katirji B, Koontz D. Disorders of peripheral nerves. In: Bradleys's Neurology in Clinical Practice. Philadelphia: Elsevier; 2012

15. Vinik AI, Holland MT, Beau JMLE, Ljuzzi FJ,
Stansberry KB, Colen LB. Diabetic neuropathies. Diabetes Care; 1992.15(12):1926-1975

16. Bahou YG. A clinical and electrodiagnostic study of diabetic neuropathy at jordan university hospital. Neurosciences; 2007.12(3):215-220

17. Bashar K. Electromyography in clinical practice: a case study approach. USA: Elsevier; 2007

18. Preston DC, Shapiro BE. Electromyography and neuromuscular disorders. 3rd ed. United Kingdom: Elsevier Saunders; 2013

19. Abraham A, Alabdali M, Qrimli M, et al. Chronic inflammatory demyelinating polyneuropathy chronic inflammatory demyelinating polyneuropathy in diabetes patients chronic inflammatory demyelinating polyneuropathy. US Neurology; 2012.11(1):47-52. DOI: http://doi.org/10.17925/USN.2015.11.01.47

20. UK Prospective Diabetes Study (UKPDS) Group. Effects of intensive blood glucose control with metformin on complications in overweight patients with type 2 diabetes (UKPDS 34). Lancet; 1998.352(Ukpds 34):854-865

21. Kinesya B, Husna M, Kurniawan SN, Ridwan M. Amplitudo sensory neuron action potential using as installation of polyneuropathy diagnosis. Malang Neurology Journal; 2018.4:7-11. DOI: http://dx.doi.org/10.21776/ub.mnj.2018.004.01.2

22. Purbasari B, Anggraini VL, Pratiwi MD, Husna M, Kurniawan SN. Diagnostic test of toronto and modified toronto scoring, monofilament test, and vibrate sensation test using $128 \mathrm{hz}$ tuning fork for diabetic polyneuropathy. Malang Neurology Journal; 2018.4:25-34.

DOI: 